\title{
Validation of DyMESH for Vehicle vs Barrier Collisions
}

\author{
Terry D. Day \\ Engineering Dynamics Corporation
}

Allen R. York II

A.R. York Engineering, Inc.

Reprinted From: Accident Reconstruction: Analysis, Simulation, and Visualization (SP-1491) 
The appearance of this ISSN code at the bottom of this page indicates SAE's consent that copies of the paper may be made for personal or internal use of specific clients. This consent is given on the condition, however, that the copier pay a $\$ 7.00$ per article copy fee through the Copyright Clearance Center, Inc. Operations Center, 222 Rosewood Drive, Danvers, MA 01923 for copying beyond that permitted by Sections 107 or 108 of the U.S. Copyright Law. This consent does not extend to other kinds of copying such as copying for general distribution, for advertising or promotional purposes, for creating new collective works, or for resale.

SAE routinely stocks printed papers for a period of three years following date of publication. Direct your orders to SAE Customer Sales and Satisfaction Department.

Quantity reprint rates can be obtained from the Customer Sales and Satisfaction Department.

To request permission to reprint a technical paper or permission to use copyrighted SAE publications in other works, contact the SAE Publications Group.

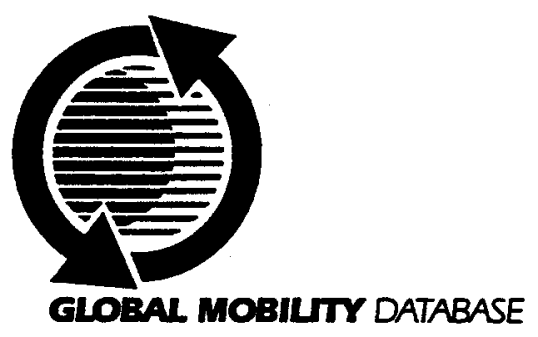

All SAE papers, standards, and selected books are abstracted and indexed in the Global Mobility Database

No part of this publication may be reproduced in any form, in an electronic retrieval system or otherwise, without the prior written permission of the publisher.

ISSN 0148-7191

Copyright $\odot 2000$ Society of Automotive Engineers, Inc.

Positions and opinions advanced in this paper are those of the author(s) and not necessarily those of SAE. The author is solely responsible for the content of the paper. A process is available by which discussions will be printed with the paper if it is published in SAE Transactions. For permission to publish this paper in full or in part, contact the SAE Publications Group.

Persons wishing to submit papers to be considered for presentation or publication through SAE should send the manuscript or a 300 word abstract of a proposed manuscript to: Secretary, Engineering Meetings Board, SAE.

\section{Printed in USA}




\title{
Validation of DyMESH for Vehicle vs Barrier Collisions
}

\author{
Terry D. Day \\ Engineering Dynamics Corporation \\ Allen R. York II \\ A.R. York Engineering, Inc.
}

Copyright (C) 2000 Society of Automotive Engineers, Inc.

\section{ABSTRACT}

A new three-dimensional collision simulation algorithm, called DyMESH (Dynamic MEchanical SHell) was recently introduced.[1]* This paper presents a validation of DyMESH for vehicle vs. barrier collisions. The derivation of the three-dimensional force vs. crush relationship was described previously.[1] Here the application of threedimensional force vs. crush curves using the outlined methodology is shown to be effective. Nonlinear force versus crush relationships are introduced for use in DyMESH. Included are numerous DyMESH collision simulations of several types of vehicles (e.g., light and heavy passenger car and sport utility) compared directly with experimental collision test results from various types of barrier tests (e.g., full frontal, angled frontal, and offset frontal). The focus here is not on the vehicle's change in velocity, but on the acceleration vs. time history. The paper shows that, while not as important for simulating velocity change, a nonlinear or piecewise linear force vs. crush relationship can improve the prediction of the acceleration vs. time history which is critical for simulations in which occupant dynamics are to be studied. The capability of prescribing a non-linear forcedeflection curve within DyMESH is illustrated in each case studied. The studies show the effect on vehicle acceleration as the vehicle stiffness models are altered. The simulation results agree favorably with experimental data.

\section{INTRODUCTION}

Numerical simulation of complex physical events is becoming more commonplace as the cost of computing power drops with advances in technology. In addition to allowing faster run times using existing or "legacy" codes, many researchers are choosing to upgrade their codes and obtain higher fidelity results in run times that are similar to

*Numbers in brackets designate references found at the end of the paper. those achieved a few years ago. An important step in the process of developing or upgrading a code or algorithm is validation with test and/or theoretical results.

The purpose of DyMESH (Dynamic MEchanical SHell) is to allow an interactive three-dimensional collision simulation of higher fidelity than has been available in the past. This paper presents simulation results using DyMESH. These results form part of the validation documentation. More validation results will be presented in the future.

DyMESH uses the discretized surfaces of a vehicle to calculate its interaction with other objects (vehicles, barriers, light poles, etc.). Figure 1 shows the general flow of the DyMESH algorithm. An important extension of existing twodimensional methodology is used to generate a threedimensional force vs. deflection (or crush) relationship. This was discussed in a previous paper. [1]

\section{TESTS USED FOR COMPARISON}

Data from vehicle crash tests are readily available from sources such as the National Highway and Traffic Safety Administration (NHTSA), The George Washington University National Crash Analysis Center (NCAC), and the Insurance Institute for Highway Safety (IIHS).

This paper contains simulations of documented full-scale tests using the DyMESH collision algorithm within the Human-Vehicle Environment (HVE) software.[7] The tests that are simulated with DyMESH are summarized in Table 1. These particular tests were selected because they vary in the size of the vehicle, the impact speed, and the impact orientation.

The authors chose to present simulations resulting from first-time runs using input parameters that are intuitive and readily available. There has been no attempt to optimize the simulations to obtain more favorable agreement with 


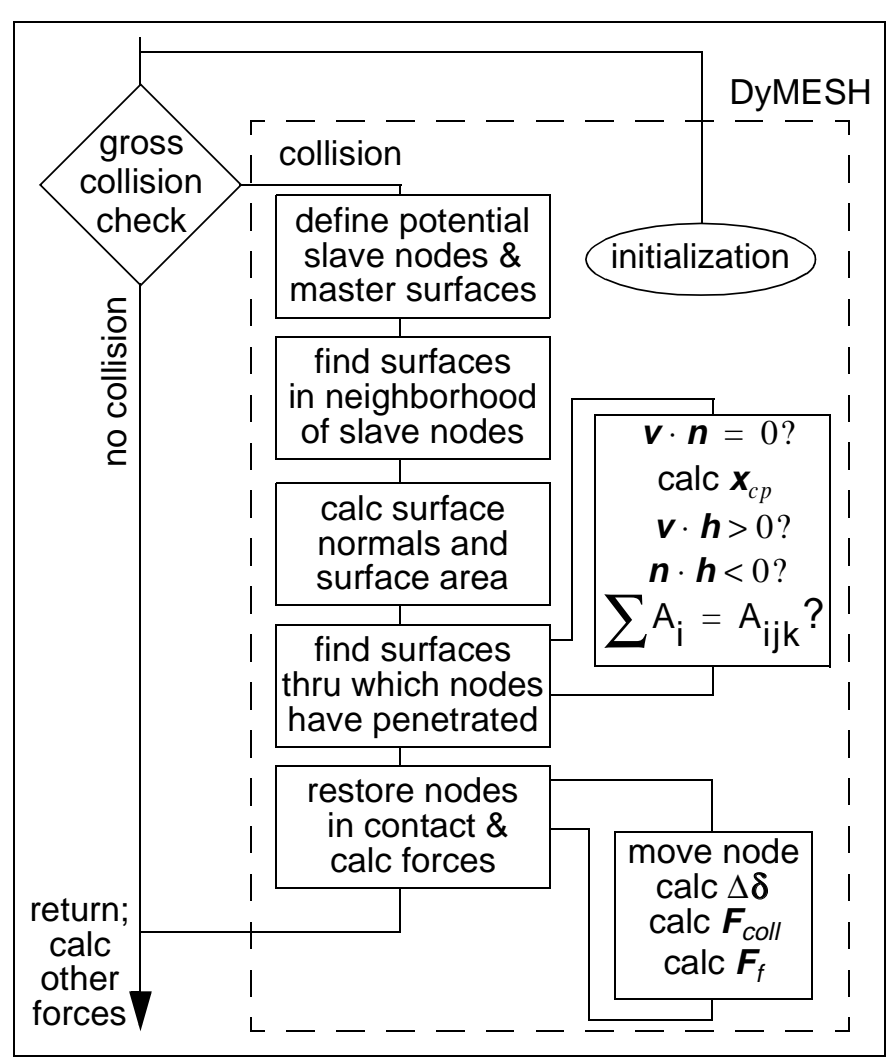

Figure 1. DyMESH Flow Chart

test data. For example, stiffness coefficients available in the HVE vehicle database are used along with standard HVE vehicle-specific properties such as rotational inertias and suspension system properties.

Table 1: Tests Used for Comparisons

\begin{tabular}{|c|c|c|c|c|}
\hline Vehicle & $\begin{array}{c}\text { Barrier } \\
\text { Type }\end{array}$ & $\begin{array}{c}\text { Impact } \\
\text { Velocity } \\
\text { (mph) }\end{array}$ & $\begin{array}{c}\text { Impact } \\
\text { Angle } \\
\text { (deg) }\end{array}$ & Ref. \\
\hline \hline $\begin{array}{c}1993 \text { Chevy } \\
\text { Suburban }\end{array}$ & $\begin{array}{c}\text { Rigid, } \\
\text { fixed }\end{array}$ & 35.0 & 0 & 2 \\
\hline $\begin{array}{c}1990 \text { Olds } \\
\text { Delta } 88\end{array}$ & $\begin{array}{c}\text { Rigid, } \\
\text { fixed }\end{array}$ & 29.6 & 60 & 3 \\
\hline $\begin{array}{c}1997 \text { Ford } \\
\text { Escort }\end{array}$ & $\begin{array}{c}\text { Rigid, } \\
\text { fixed }\end{array}$ & 35.1 & 0 & 14 \\
\hline $\begin{array}{c}1996 \text { Ford } \\
\text { Explorer }\end{array}$ & $\begin{array}{c}\text { Deform- } \\
\text { able, } \\
\text { fixed }\end{array}$ & 39.1 & 0 & 5 \\
\hline
\end{tabular}

\section{DYMESH SIMULATIONS}

The DyMESH algorithm requires a force-deflection relation- ship for each vertex to calculate collision forces. In the past, simulation codes have used a linear stiffness $K$ to model crush forces.[8,9] Later, linear force vs. crush curves with the coefficients commonly known as $A, B$, and $G$ were implemented.[10,11] Linear force-deflection models are simple and easy to implement. However, the true form of the force-deflection curve is rarely linear and is often the subject of technical papers.[12,13]

DyMESH can use virtually any force vs. deflection relationship. A derived force vs. displacement curve from a NHTSA barrier impact test is shown in Figure 2 (thick line). These

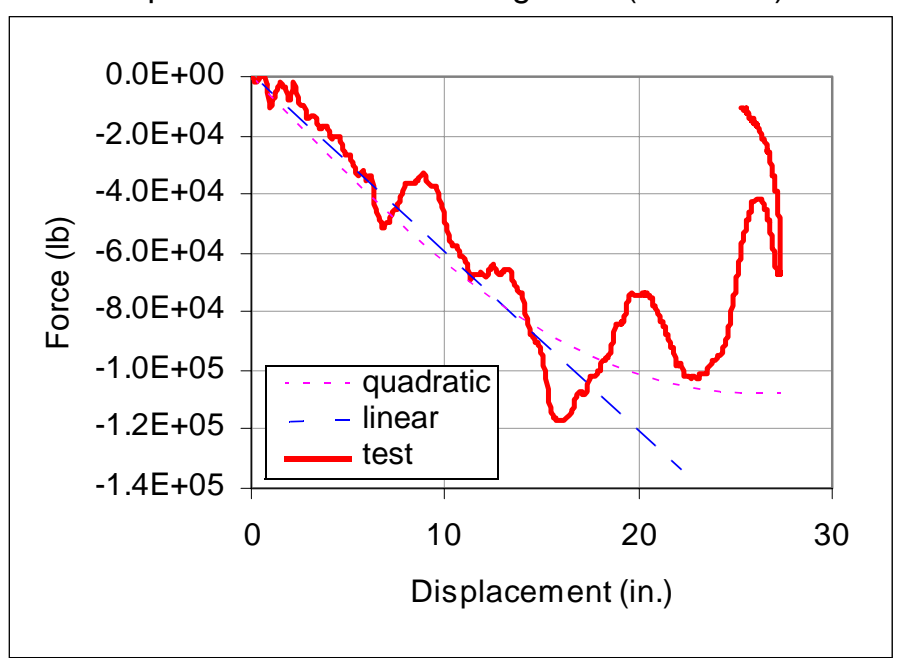

Figure 2. Force vs. Displacement

data are from the load cells in a barrier test of a 1997 Ford Escort.[6] Overlaid on this plot are two possible approximations to the curve - a linear and quadratic function. Kerkhoff et. al. found in tests that crushed the same vehicle to different levels that different $A$ and $B$ stiffness coefficients would be derived as shown in Figure 3.[13] That is, stiffness coefficients were calculated following each test which crushed the vehicle to a different level. The legend in the plot of Figure 3 denotes the impact velocity and resulting crush (mph/in.). He suggests a quadratic functional relationship may be appropriate.

The simulations presented in this paper use a variety of force vs. deflection relationships. However, they are all based on the standard $A$ and $B$ coefficients as a starting point. The researcher or reconstruction analyst must choose the relationship carefully if occupant dynamics are of interest. Varying the force on the vehicle during a collision alters the acceleration time history and will affect the response of the occupant.

In the examples that follow, a comparison of acceleration history is made between the simulation results and test results. Emphasis is not placed on the comparison to

*Displacement is the same as crush as long as the vehicle is in contact with the barrier. The last portion of the "test" curve indicates vehicle rebound. 
change in velocity as this can potentially be matched exactly by altering the unloading slope of the force vs. deflection relationship. These examples use an unloading slope of ten times the initial loading slope.

The first two example simulations (Suburban and Delta 88) illustrate DyMESH when interfaced with a three-degree-offreedom (DOF) solver. That is, mesh interactions are calculated in three dimensions, but only the resulting $x-y$ and yaw motion (3-DOF) are obtained in the solution. The 3DOF simulation is usually referred to as being two-dimensional. The last two simulations (Escort and Explorer) include the 6-DOF solver which forms the complete threedimensional simulation.

\section{SUBURBAN FRONTAL BARRIER TEST}

The set-up for the test of the 1993 Suburban is shown in Figure 4. In this test the vehicle impacts the rigid barrier at $35 \mathrm{mph}$ in an orientation perpendicular to the barrier. The vehicle weighed 6,267 lb for the test.

The HVE vehicle-specific values of stiffness are used:

$A=295 \mathrm{lb} / \mathrm{in}$ and $B=87.5 \mathrm{lb} / \mathrm{in}^{2}$ which were determined from crash tests. When using a linear force-deflection relationship, DyMESH converts these parameters to be used in three-dimensional analyses by dividing $A$ and $B$ by 30 in., which is assumed to be the effective, nominal height (in the $z$ direction) of vehicle crush in a barrier test.

A summary of the simulation and test results is listed in Table 2. A range of values is given for the three DyMESH simulations that were carried out with different force-deflection functions. Figure 5 shows the deformed shape of the Suburban following impact with the barrier. The vehicle shown used the quadratic force-deflection curve in the simulation. Note the bumper and license tag holder recovered more deformation than the surrounding areas due to the fact that they were deformed more in the collision. Thus,

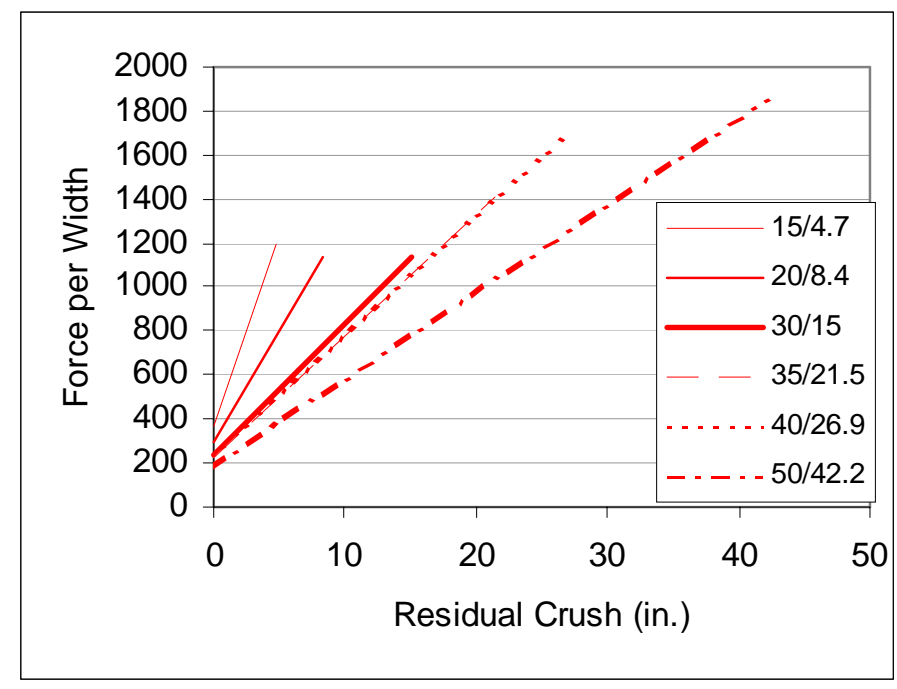

Figure 3. Linear Force-Crush Curves Derived from Tests on the Same Vehicle

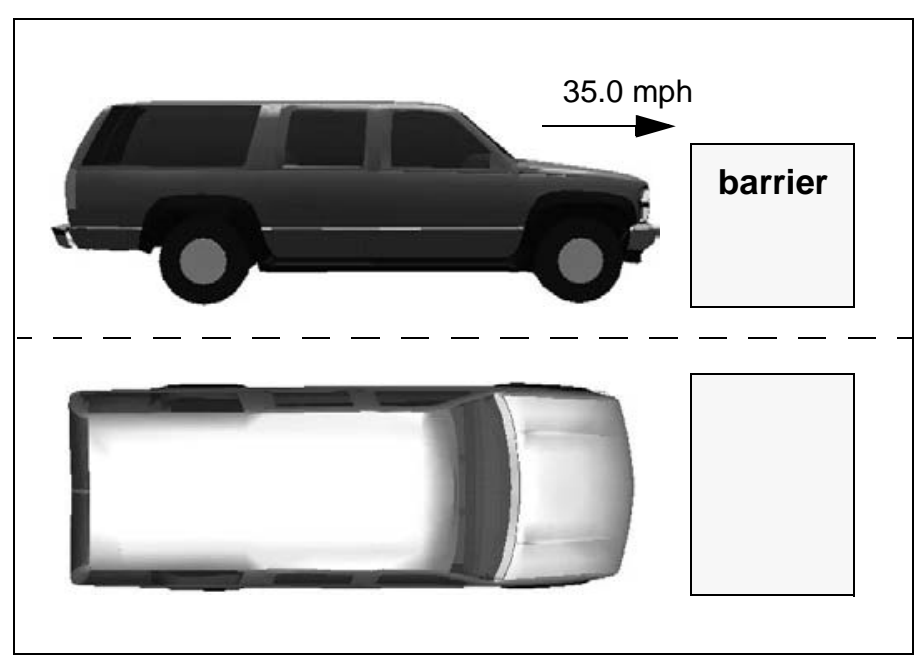

Figure 4. Suburban Test Set-up

these areas are observed to protrude in the figure.

Table 2: Suburban 35 MPH Barrier Impact Summary

\begin{tabular}{|c|c|c|}
\hline Item & Peak G's & $\begin{array}{c}\Delta \mathrm{V} \\
(\mathrm{mph})\end{array}$ \\
\hline \hline DyMESH & $23-40$ & $35-45$ \\
\hline Test & 25 & 39.8 \\
\hline
\end{tabular}

Figure 6(a) shows the force-deflection models used in the three analyses. The unloading slope is plotted at the end of each curve for presentation purposes only; unloading can begin anywhere in the loading cycle. The dark line shows the linear relationship using the $A$ and $B$ coefficients modified to yield a function that is Force/Area instead of Force/ Width. Figure $6(\mathrm{a})$ also shows a quadratic function $(\mathrm{F} / \mathrm{A}=$ $\left.-0.057 x^{2}+3.57 x+6.5\right)$ that has a higher initial slope and a lower slope that gradually decreases after about seven inches of crush. This curve was obtained by manually

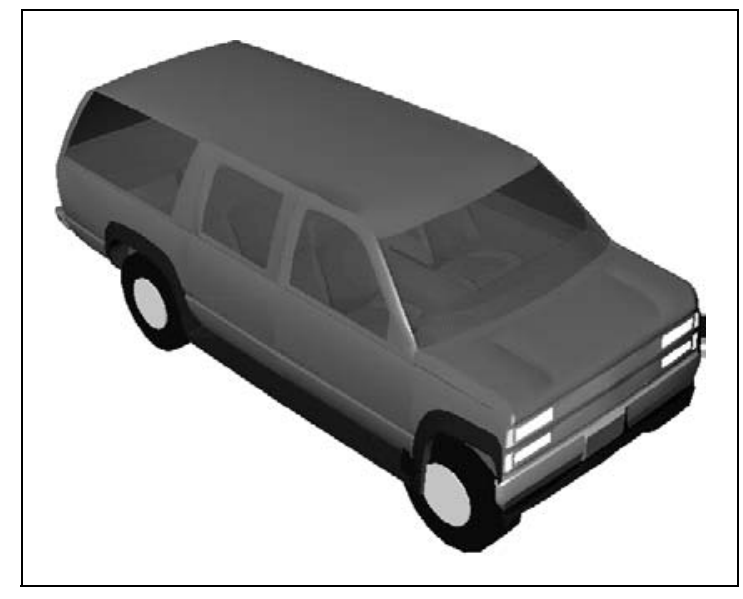

Figure 5. Suburban Deformation After the Collision 
adjusting points on the linear curve and using curve fitting software to derive the coefficients. The third line on the plot shows the linear model with force saturation at $10 \mathrm{in}$. crush.

Figure 6(b) compares the acceleration histories of the three simulations with test data. The trends are as-expected. The force-deflection model with the highest force (linear model) results in the highest acceleration and smallest duration. The quadratic model estimates the peak G's better, and has a slightly longer pulse duration than the linear model result. The force saturation model underestimates the peak G's and overestimates the pulse duration.

The pulse rise time is more closely matched by the quadratic model. This is consistent with the steeper initial slope of this model. The linear and force saturation models are the same until about $\mathrm{t}=30 \mathrm{~ms}$ when the force is limited to be constant. The quadratic model tracks the overall response better.

The peak G's are overpredicted by $27 \%$ ( 31.8 compared to $25.1)$ by the quadratic model. The acceleration increase at $\mathrm{t}=90 \mathrm{~ms}$ from $29 \mathrm{G}$ to $31.8 \mathrm{G}$ is due to the start of restitution. All of the models show this characteristic increase in acceleration at the beginning of the restitution phase of the collision. This amplification is due to the numerical idealization of the problem. Nearly all of the deformed area of the vehicle begins restitution at exactly the same time. Since the barrier is perfectly flat all of the restitution force is generated immediately. This is in contrast to a real event where the existence of a non-perfect barrier and various hard and soft spots across the width of the vehicle would cause some staggering in time of the restitution of the front of the vehicle.

Figure 6(c) shows the velocity history of the three simulations and the test. The linear and quadratic match fairly well until the end when they both overpredict rebound. A steeper unloading slope could be used to reduce the overprediction.

As an example consider the same simulation run with and without restitution. A simulation without restitution is a plastic impact resulting in no residual velocity and no recovery of any damage. In this case, the slope of the unloading portion of the force-deflection curve is infinity (vertical) so the force immediately drops to zero. When restitution is used, the unloading curve is followed which incrementally reduces the force as some of the deformation is recovered (Figure 6(a)). Figure 7 shows the velocity history using the linear force-deflection model with and without restitution. As expected without restitution the velocity of the vehicle after the collision is zero. The difference in the change in velocity is about $12 \mathrm{mph}$ or $34 \%$ of the impact velocity when restitution is used. This high value does, in fact, indicate that the unloading slope used allows recovery of too much deformation.

DELTA 88 ANGLED FRONTAL BARRIER TEST

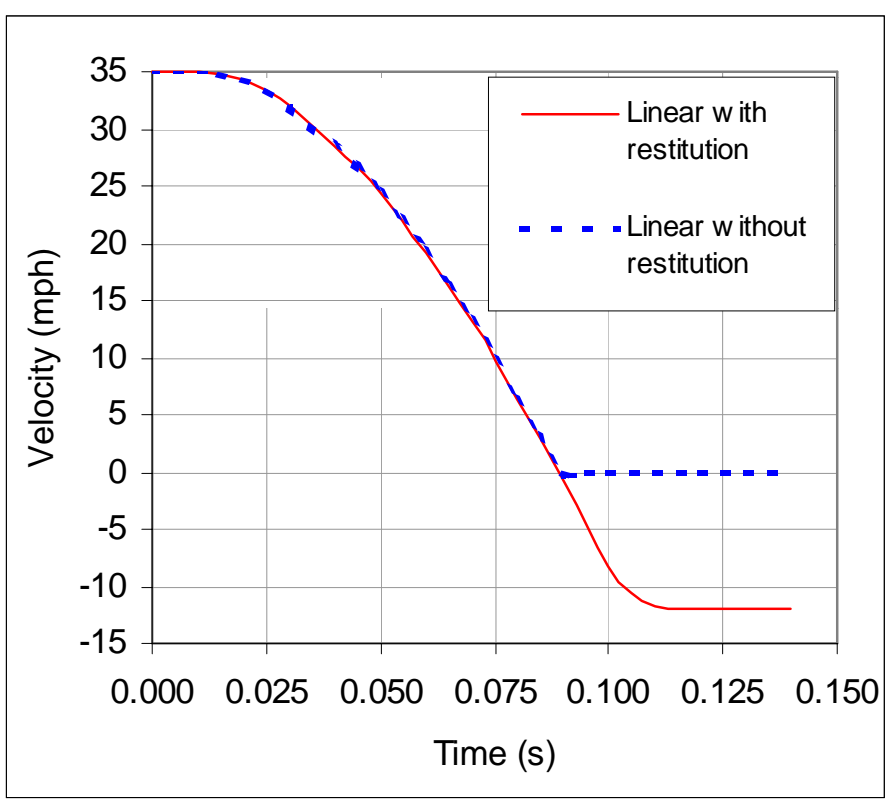

Figure 7. Velocity History With and Without Restitution

The test set-up for the 1990 Delta 88 angled barrier impact is shown in Figure 8 . In this test the $3,810 \mathrm{lb}$ vehicle impacts the rigid barrier at $29.6 \mathrm{mph}$ with a 30 degree angle between the vehicle and the barrier.

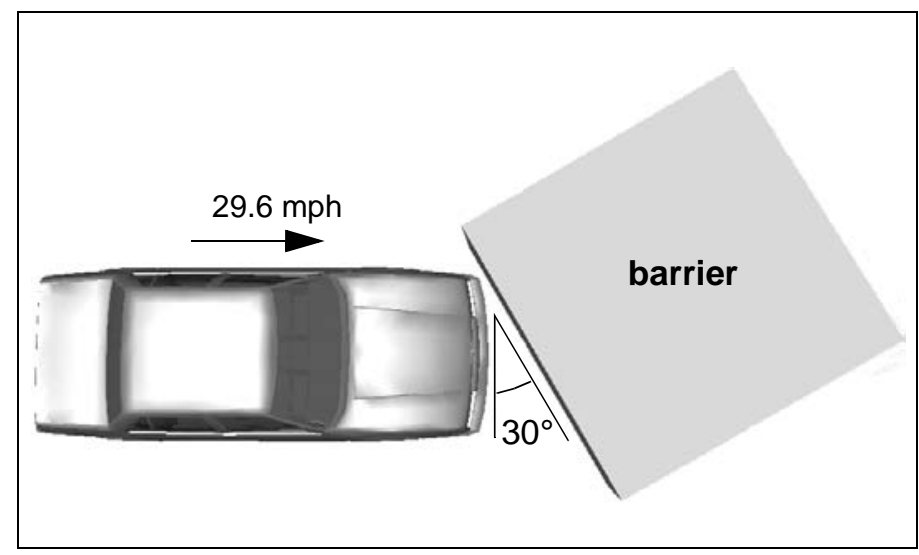

Figure 8. Delta 88 Test Set-up

A summary of the simulation and test results is listed in Table 3. As before, a range of values is given for the three DyMESH simulations that were carried out. A coefficient of friction of 0.2 is used between the barrier and the vehicle. Figure 9 shows a typical deformed shape of the Delta 88 following impact with the barrier.

Table 3: Delta 8830 MPH Barrier Impact Summary

\begin{tabular}{|c|c|c|}
\hline Item & Peak G's & $\begin{array}{c}\Delta \mathrm{V} \\
(\mathrm{mph})\end{array}$ \\
\hline \hline DyMESH & $14-18$ & $24-25$ \\
\hline Test & 21 & 29 \\
\hline
\end{tabular}




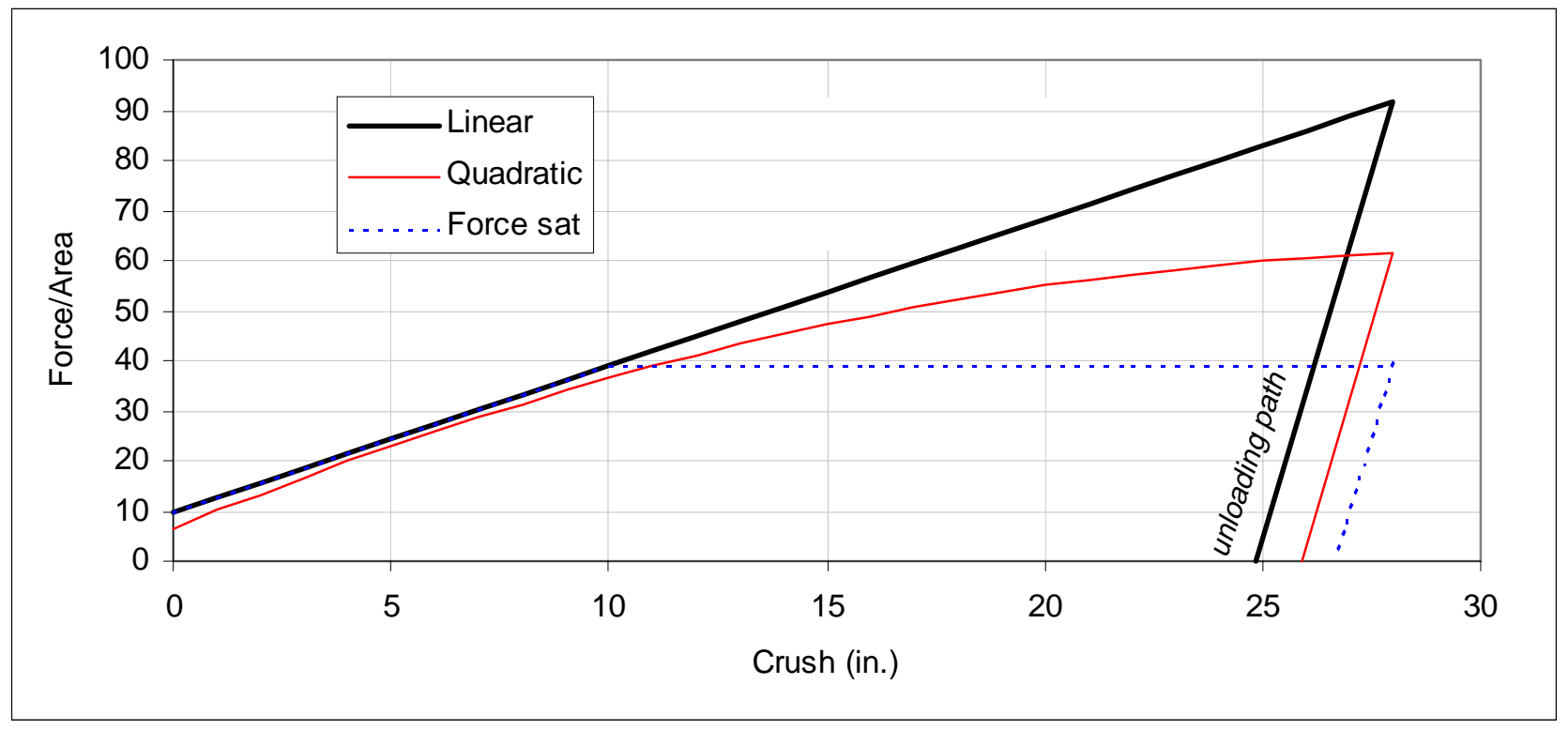

(a)

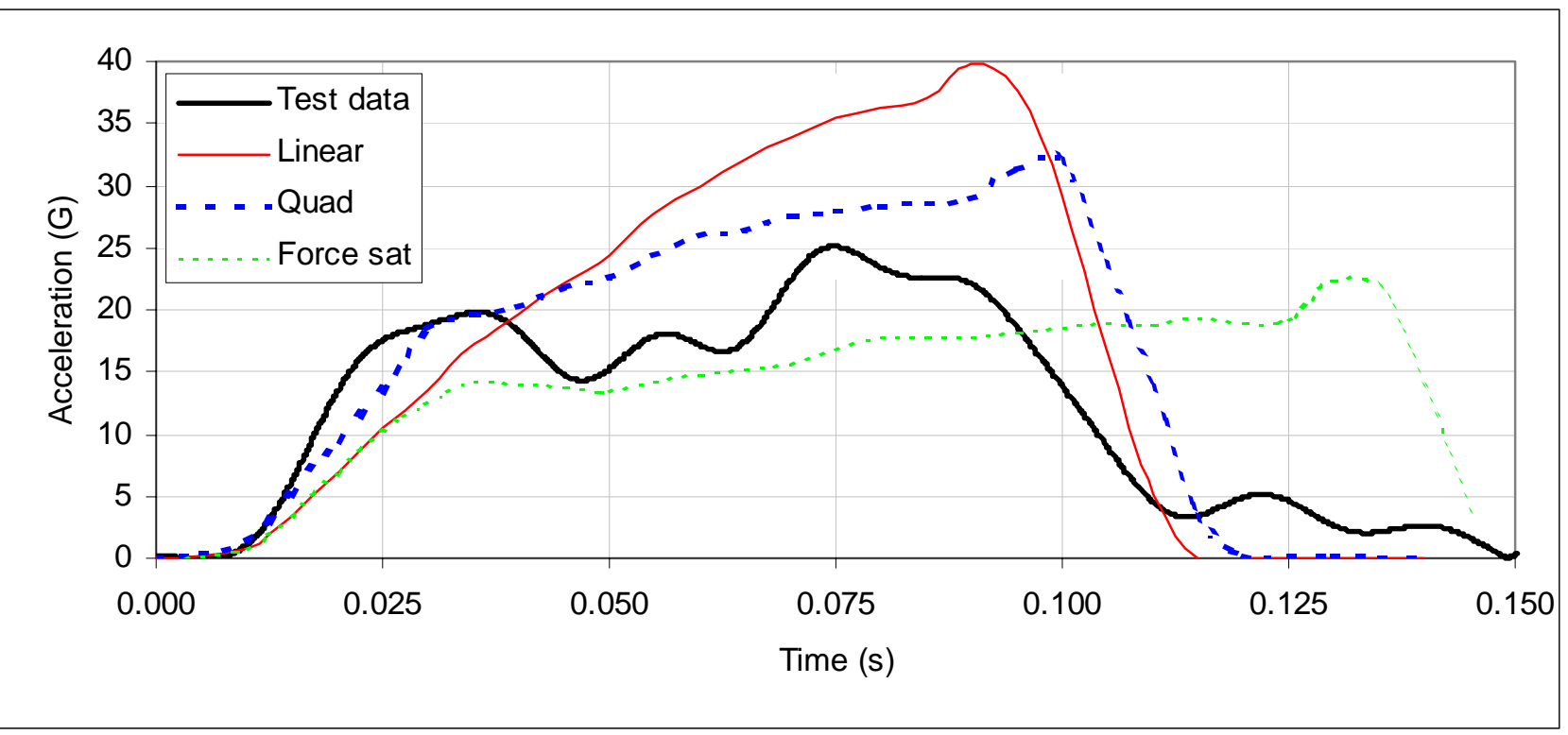

(b)

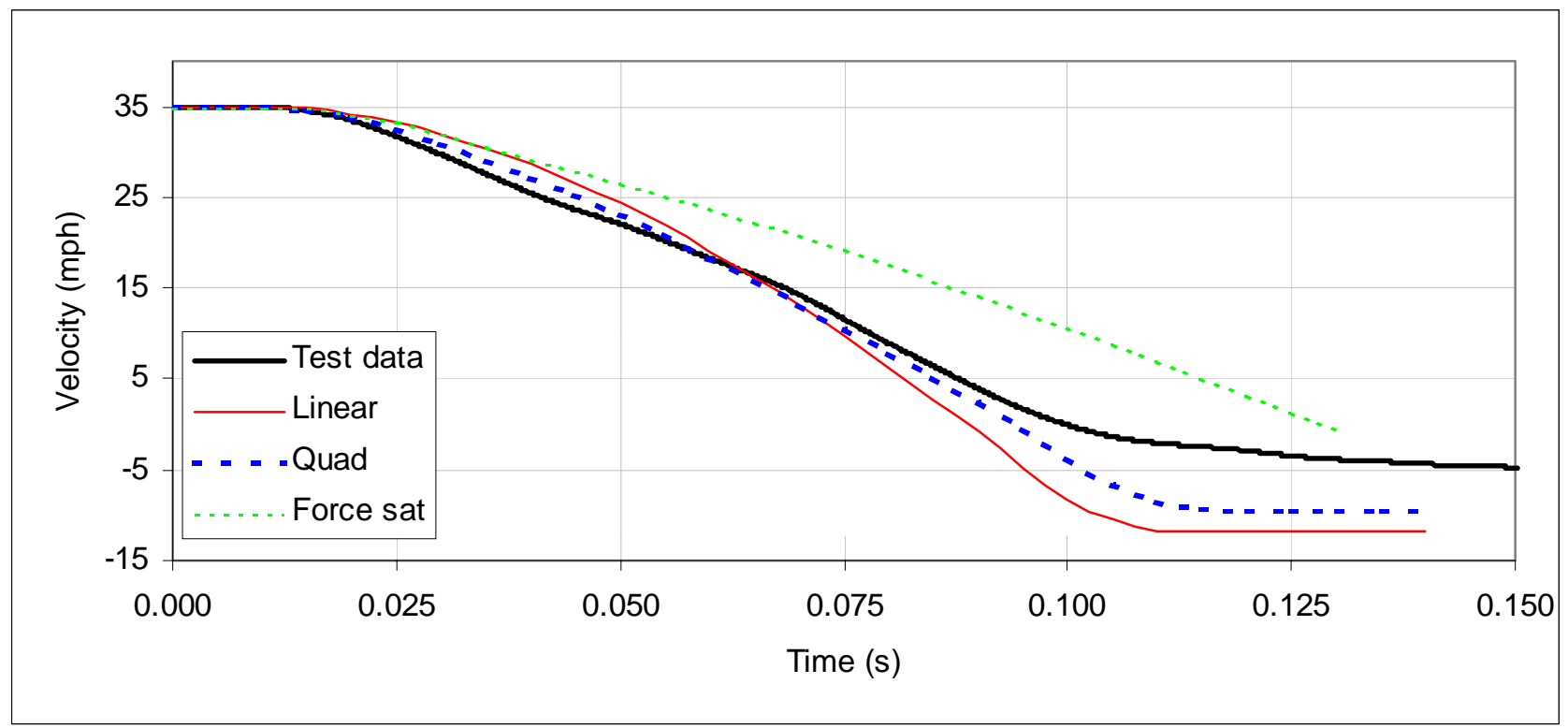

(c)

Figure 6. Suburban Simulation: (a) Force-Crush Curves, (b) Comparison of Acceleration Data, and (c) Comparison of Velocity Data 


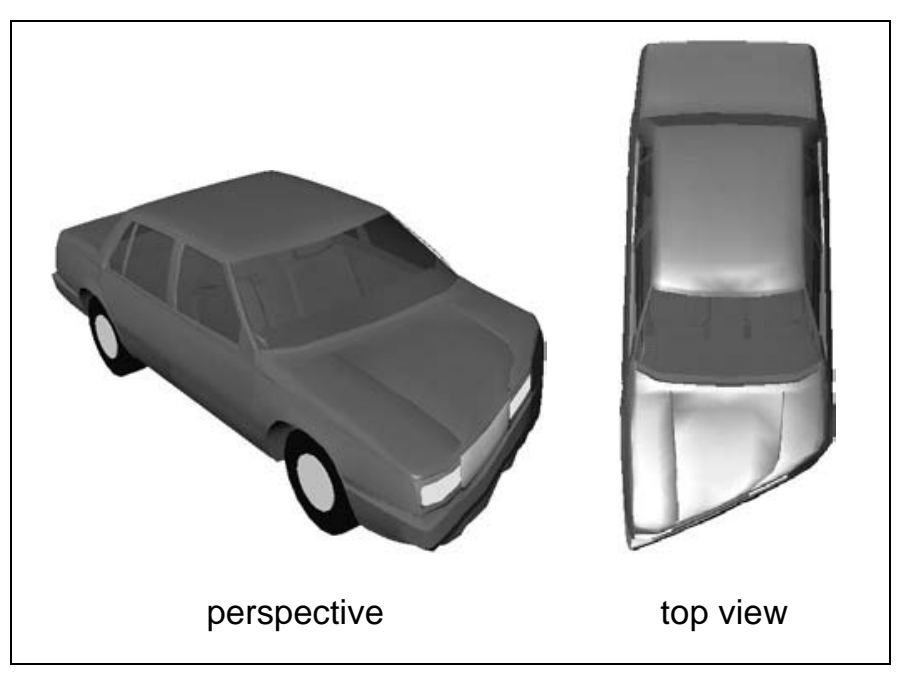

Figure 9. Delta 88 Deformed Vehicle

Figure 11(a) shows the force-deflection models used in the three analyses. The unloading slope is plotted at the end of each curve for presentation purposes only; unloading can begin anywhere in the loading cycle. The dark line shows the linear relationship using the modified $A$ and $B$ coefficients. Figure 11(a) also shows a quadratic function $(F / A=$ $\left.-0.032 x^{2}+2.02 x+5.2\right)$ that has similar form as the previous example simulation. The third line on the plot shows the linear model with a force saturation at $10 \mathrm{in}$. crush. The unloading slope is shown as a thin line with an arrow and is the same for each model.

Figure 11(b) compares the $x$-axis acceleration histories of the three simulations with test data. The trends are somewhat non-intuitive, but reasonable. The difference in peak G's between the linear model and quadratic model is not as dramatic as in the perpendicular barrier test. However, the peak G's do follow the same order with the highest being the linear model $(19+G)$, next the quadratic model (19), and finally the force saturation model (15 G). The linear model estimates the peak G's better and the pulse duration is slightly longer than the quadratic model result. As before, the force saturation model underestimates the peak G's; however, the pulse duration estimate is closer than either of the other two models.

As with the Suburban barrier test simulation, the pulse rise time is more closely matched by the quadratic model which is consistent with the steeper initial slope of this model. The linear and force saturation models are the same until about $\mathrm{t}=43 \mathrm{~ms}$.

The peak G's are underpredicted by $10 \%$ (19 compared to 21) by the linear model. Restitution does not cause a jump in the acceleration pulse for this simulation as the crushed portion of the vehicle makes and loses contact with the barrier at different times. In fact, it's possible that parts or all of the vehicle undergo restitution following contact with the barrier which would not alter the total external force on the vehicle. In this case, restitution would not affect the vehicle acceleration since no external forces are generated, but the damage profile would be affected by the recovery of deformation.

Figure 11(c) shows the $x$-axis velocity history of the three simulations and the test. It's difficult to draw a significant distinction between the curves. However, the quadratic force-deflection model does predict the overall change in velocity the best.

It is interesting to note the effect that the friction coefficient between the vehicle and barrier has on the solution. This parameter makes a dramatic difference in the change in velocity as seen in Figure 10 where two simulations using the quadratic force-deflection model are compared. Using a coefficient of friction of 0.2 versus 0.4 makes over a $7 \mathrm{mph}$ difference in the change in $\mathrm{x}$-axis velocity.

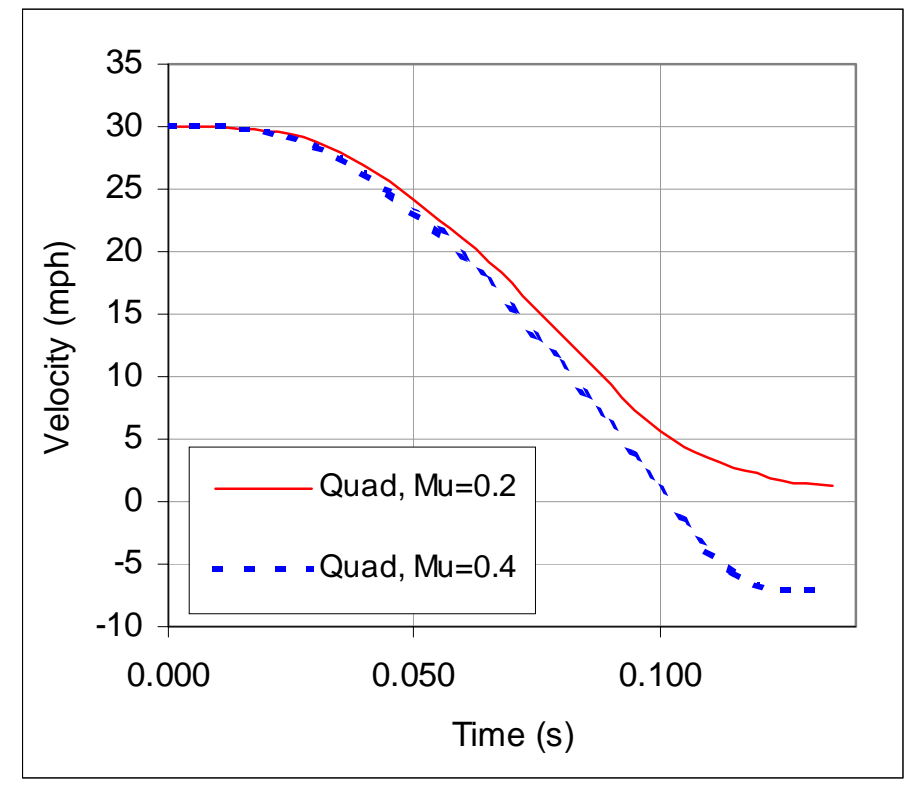

Figure 10. Comparison of Vehicle X-Velocity for Simulations Using Two Friction Values

Figure 12 shows a time sequence of the DyMESH trajectory. It is observed that the character of the motion of the vehicle follows that shown in the test video. The front portion of the vehicle is forced to the right by the barrier before the rear of the vehicle experiences significant rotation. It is interesting to note that in the case cited above when the friction coefficient of the surface was changed to 0.4 that the character of the vehicle motion changed. 

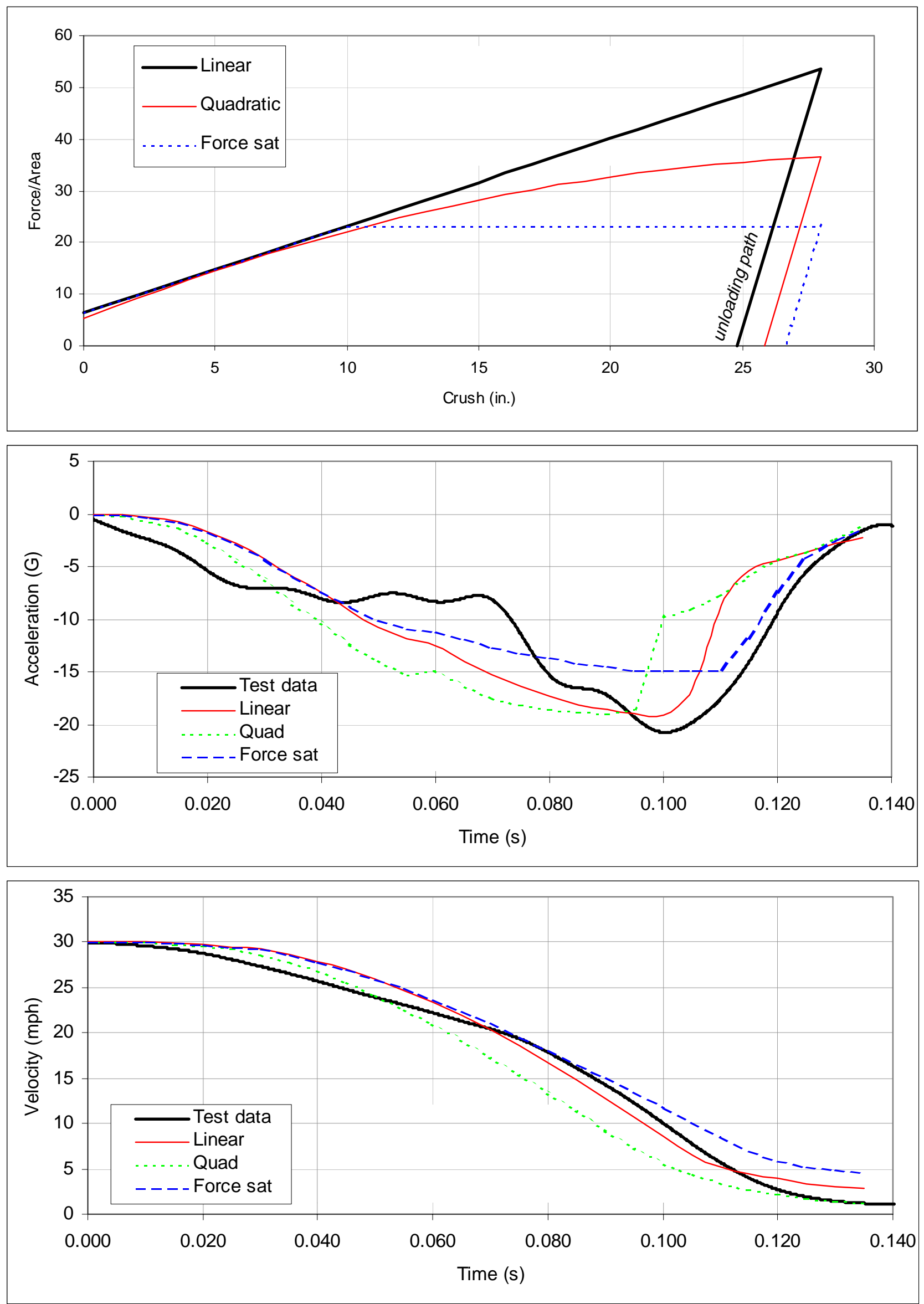

(c)

Figure 11. Delta 88 Results: (a) Force-Crush Curves, (b) Comparison of Acceleration Data, and (c) Comparison of Velocity Data 


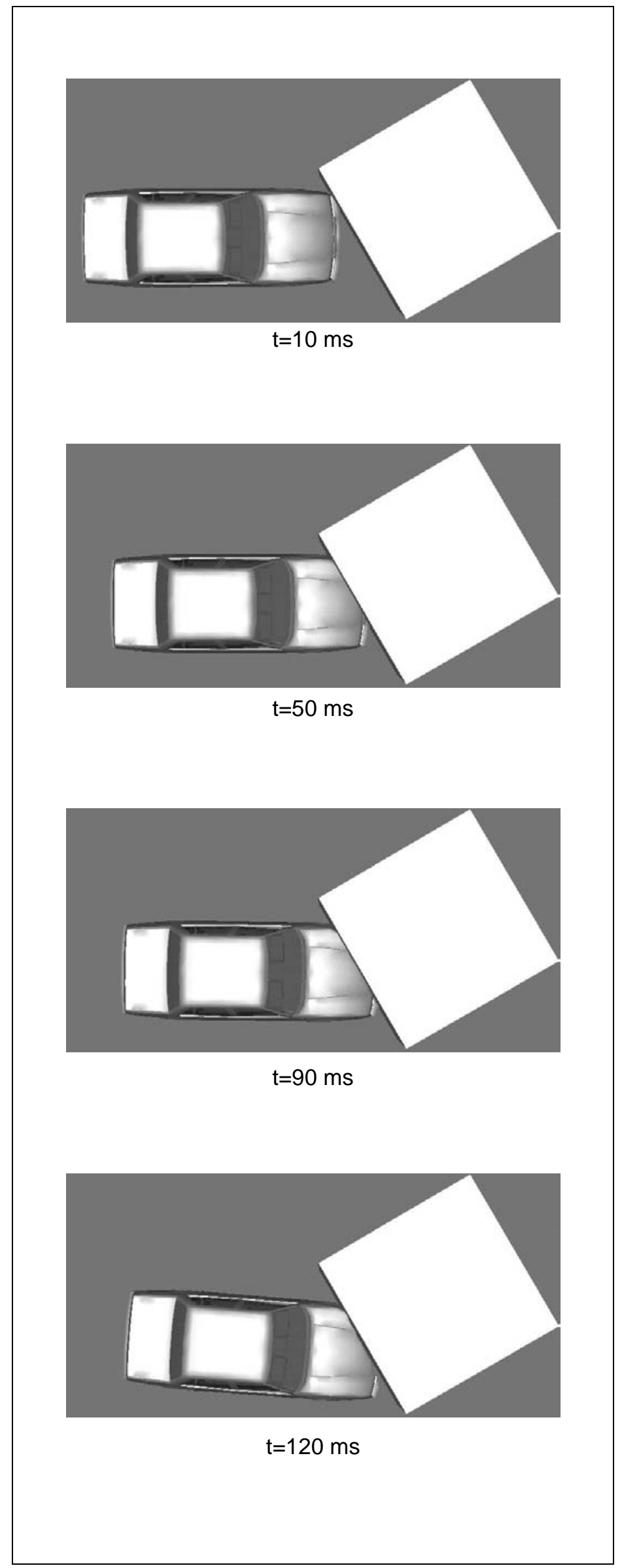

Figure 12. Vehicle Trajectory 
The test set-up for the 1993 Ford Escort barrier impact is shown in Figure 13. A government report provides all of the relevant information about the test.[14]

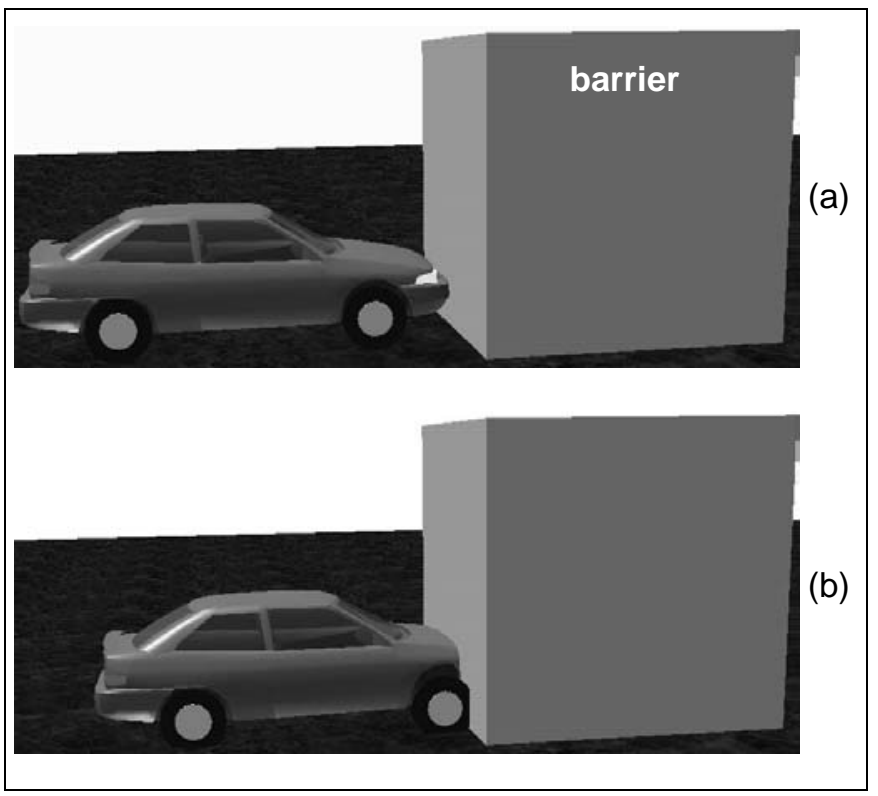

Figure 13. Ford Escort (a) Test Set-up and (b) following the Impact

The Escort impacts the rigid barrier at $35.1 \mathrm{mph}$ in a perpendicular orientation to the barrier (zero degrees). The vehicle weighed 2,963 lb for the test.

A summary of the simulation and test results is listed in Table 4. As before, a range of values is given for the three DyMESH simulations that were carried out. Figure 14 shows a typical deformed shape of the Escort following impact with the barrier.

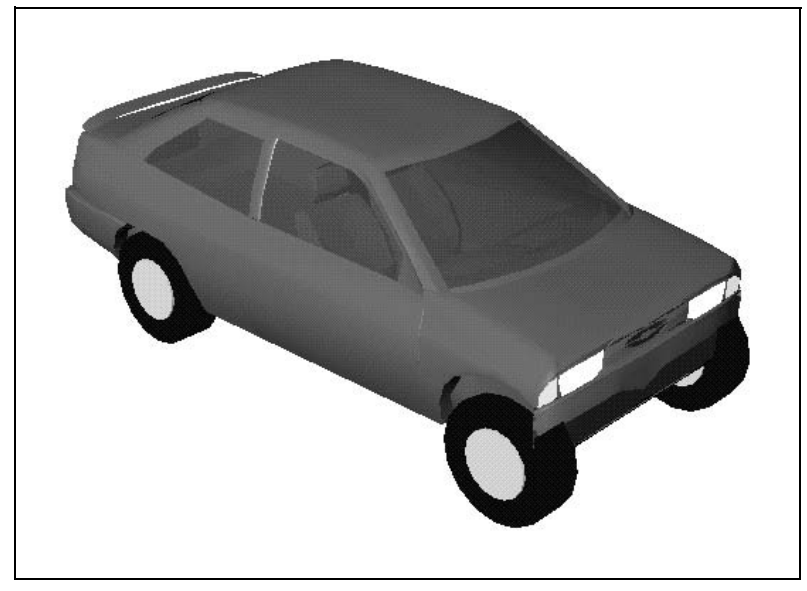

Figure 14. Ford Escort Damage Profile
Table 4: Ford Escort 35 MPH Barrier Impact Summary

\begin{tabular}{|c|c|c|c|}
\hline Item & $\begin{array}{c}\text { Peak } \\
\text { G's }\end{array}$ & $\begin{array}{c}\text { Max } \\
\text { Crush } \\
\text { (in.) }\end{array}$ & $\begin{array}{c}\Delta \mathrm{V} \\
(\mathrm{mph})\end{array}$ \\
\hline \hline DyMESH & $20-43.5$ & $23.7-36$ & $38-45$ \\
\hline Test & 40.5 & 19.8 & 39 \\
\hline
\end{tabular}

Figure 15(a) shows the force-deflection models used in the three analyses. The unloading slope is plotted at the end of each curve for presentation purposes only; unloading can begin anywhere in the loading cycle. The dark line shows the linear relationship using the modified $A$ and $B$ coefficients. Figure 15(a) also shows a quadratic function ( $F / A=$ $\left.-0.05 x^{2}+4.5 x+3.0\right)$. The third line on the plot shows the linear model with a force saturation at $10 \mathrm{in}$. crush.

Figure 15(b) shows the acceleration histories where the linear model produces agreement with peak G's to within five percent. However, all of the models produce peak acceleration at a later time than observed in the test. The linear model agrees with the velocity change in the test to within $14 \%$.

As before, the initially steeper quadratic force vs. deflection model causes a more rapid initial pulse rise time than the linear and force saturation models. The linear and force saturation models show the same early acceleration response as they should. The difference between the quadratic model and linear model are small, but the quadratic model appears to track the overall response better. The force saturation model is obviously too soft as the peak G's are underestimated by about 50 percent.

The change in velocity is overpredicted by both the linear and quadratic models. This indicates the unloading slope should be higher so that less deformation is recovered. 


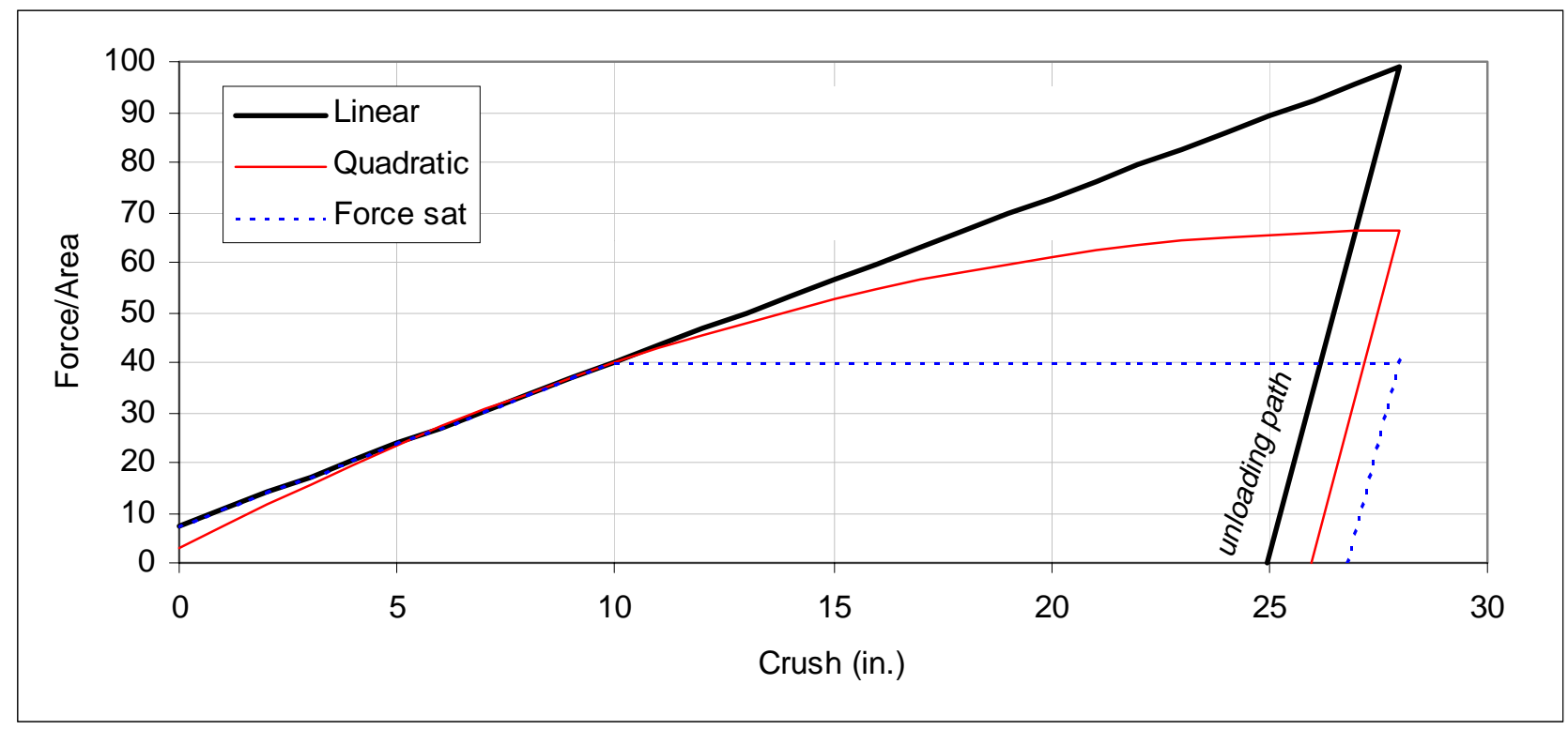

(a)

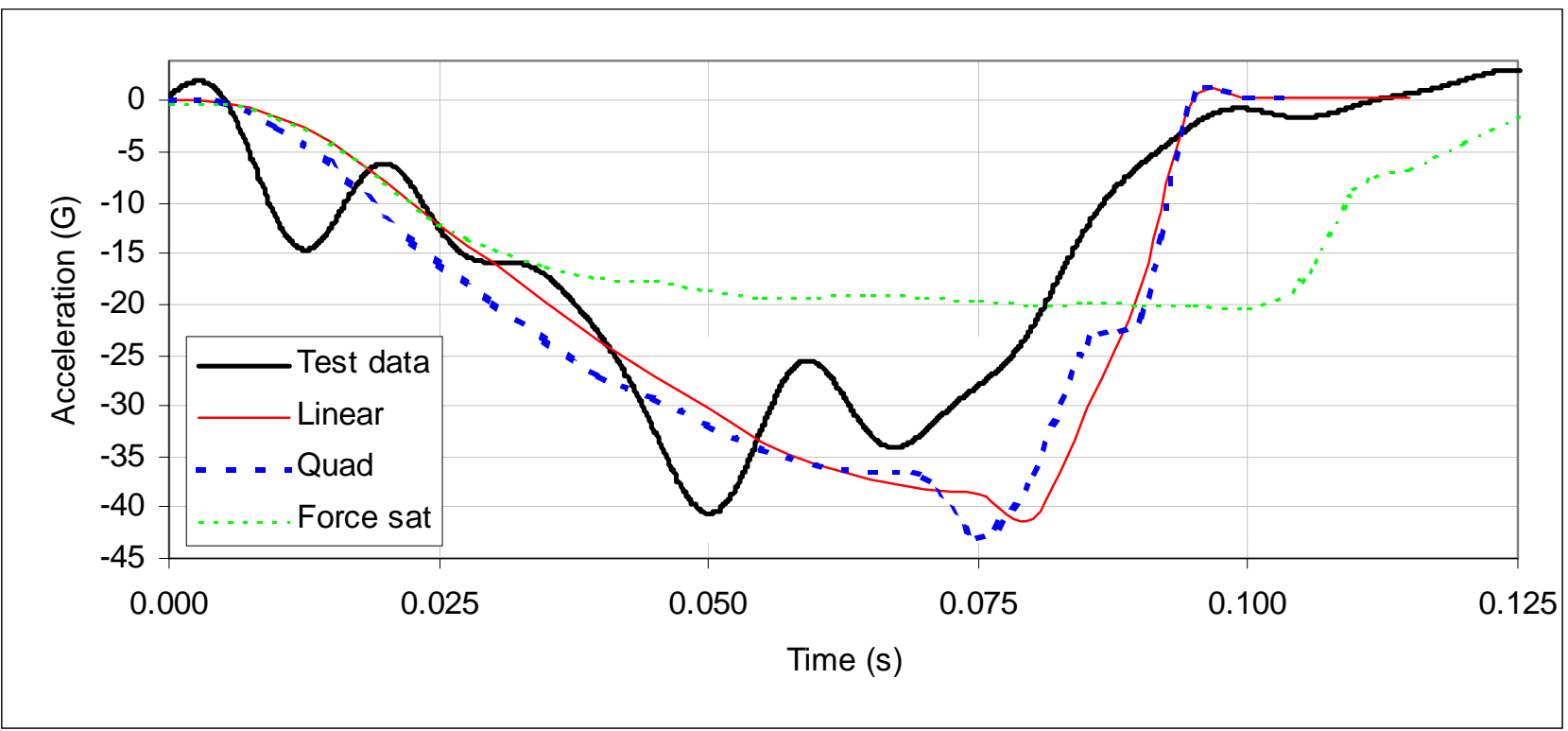

(b)

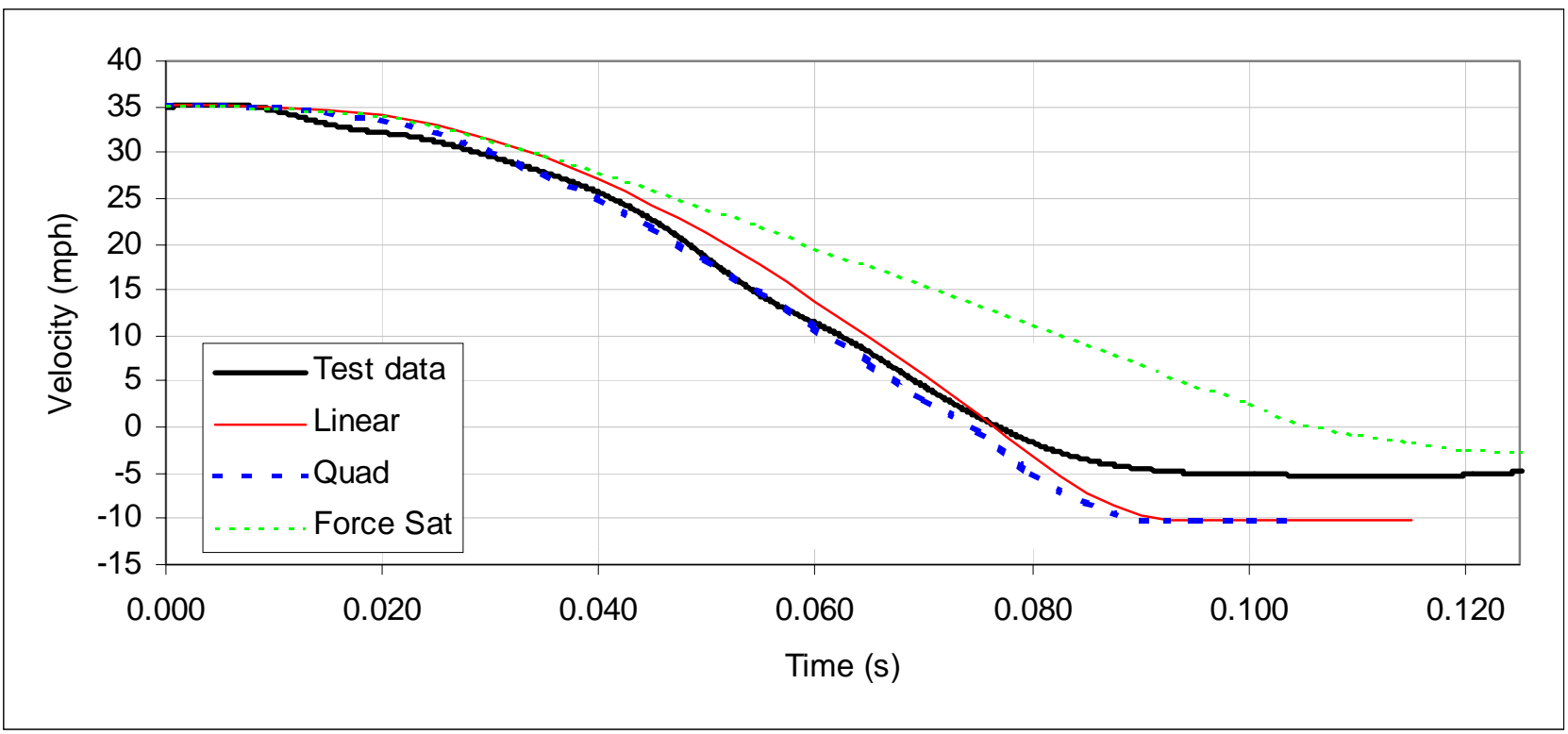

(c)

Figure 15. Ford Escort Results: (a) Force-Crush Curves, (b) Comparison of Acceleration Data, and (c) Comparison of Velocity Data 


\section{FORD EXPLORER OFFSET FRONTAL BARRIER TEST}

The test set-up for the 1996 Ford Explorer offset barrier test is shown in Figure 16. A special deformable barrier is used by the Insurance Institute for the $40 \mathrm{mph}$ offset crash test. The barrier overlaps the driver's side of the vehicle 40 percent. An approximation to this barrier is used in the simulation. Only the front, deformable portion of the barrier is modeled. The barrier is allowed to deform, but not to translate or rotate.

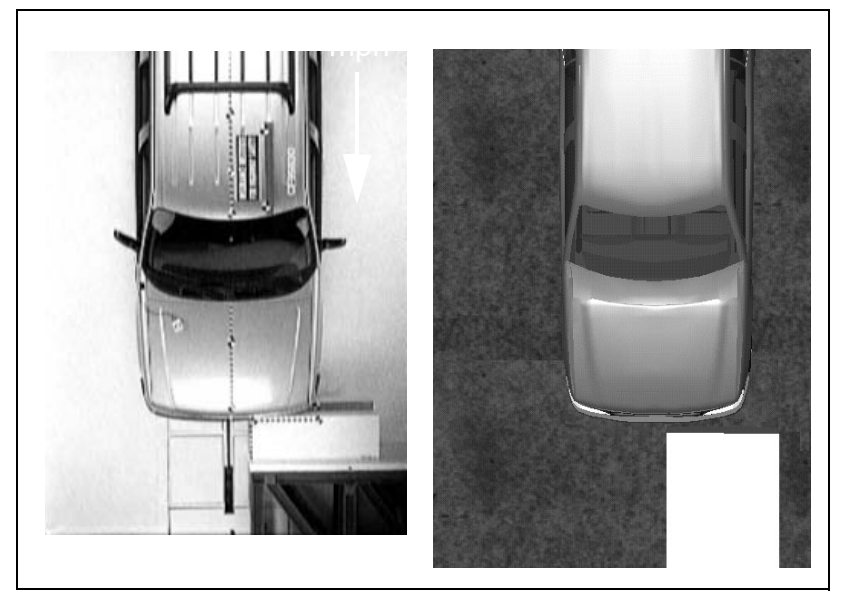

Figure 16. Ford Explorer Test Set-up and Simulation Set-up

The test vehicle weighed approximately $4500 \mathrm{lb}$ and the measured impact speed was $39.1 \mathrm{mph}$. Stiffness values of $A=335 \mathrm{lb} / \mathrm{in}$ and $B=153.6 \mathrm{~b} / \mathrm{in}^{2}$ are used in the simulation.

The authors obtained a technical description of the deformable barrier from the Institute (Figure 17). The barrier is

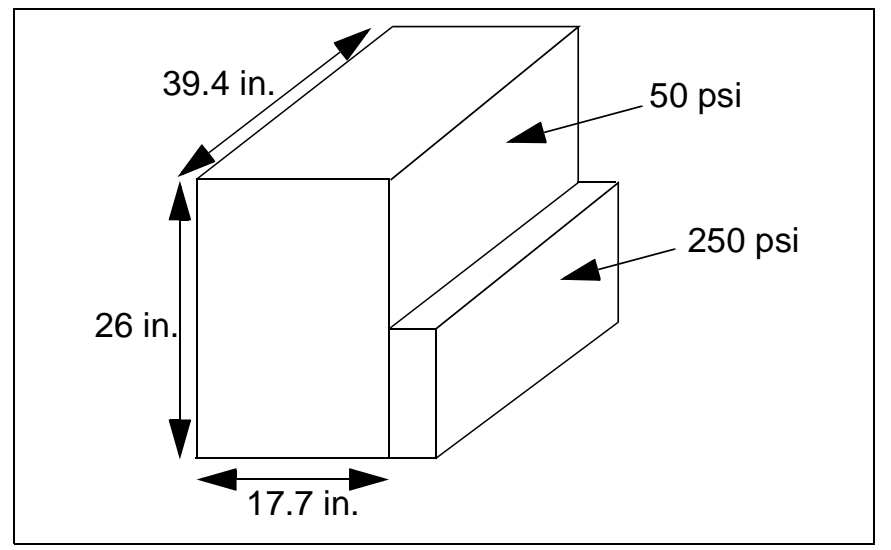

Figure 17. Deformable Barrier Geometry

composed of a 3.5-inch thick bumper simulator that is fabricated from 250 psi honeycomb. The bumper simulator is attached to a 50 psi honeycomb base. This base is attached to a nearly rigid frame. To approximate the response of the barrier, the force-deflection relationship shown in Figure 18 is used. The sharp increase at the end of the curve simulates "lock-up" of the honeycomb and the nearly rigid response of the barrier frame.

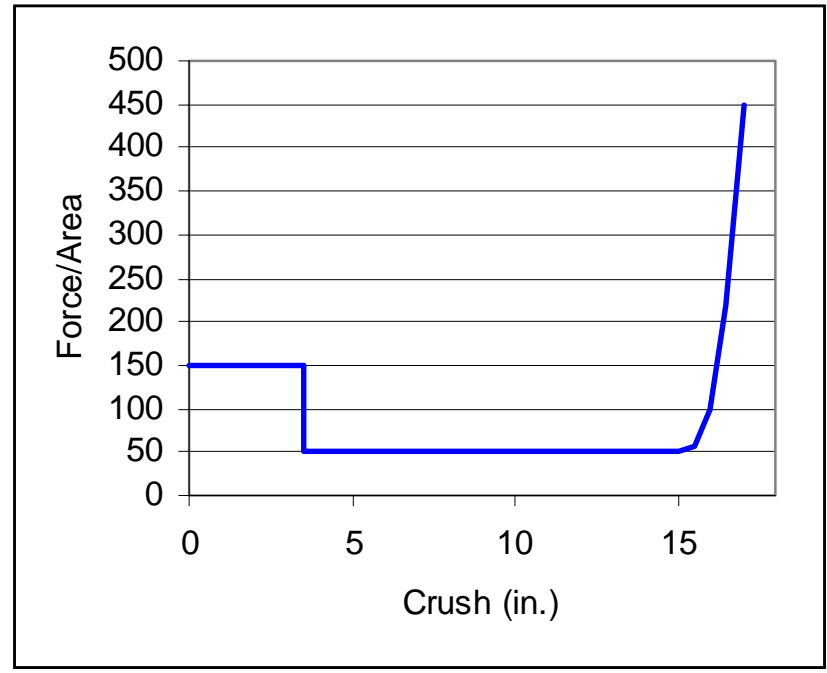

Figure 18. Deformable Barrier Force-Deflection Relationship

Simulations are presented using the three different forcedeflection relationships already discussed (Figure 20(a)). The quadratic function is $\left(F / A=-0.01 x^{2}+6.5 x+7.0\right)$. Table 5 lists a summary of the test and simulation results. The range of results agree well with the test data for peak acceleration, change in velocity, and maximum crush.

Table 5: Explorer 40 MPH Barrier Impact Summary

\begin{tabular}{|c|c|c|c|}
\hline Item & Peak G's & $\begin{array}{c}\text { Max } \\
\text { Crush } \\
\text { (in.) }\end{array}$ & $\Delta \mathrm{V}$ (mph) \\
\hline \hline DyMESH & $24-32.5$ & $26.4-27.6$ & $43.1-43.4$ \\
\hline Test & 31.5 & 28.3 & 45 \\
\hline
\end{tabular}

Figure 19(a) shows the undamaged vehicle and (b) and (c) show a representative example of the damage profile of the vehicle just following separation from the barrier. The wheel displacement option normally available in HVE was not available for this simulation, so the left front rear wheel appears in its undeformed location. The wheels are not a part of the collision algorithm so no collision forces are generated by the wheels. They do, however, have friction forces with the road surface which are passed through the suspension system to the vehicle. It is expected that not displacing the wheels produces a negligible amount of error in the simulation.

It is seen in Figure 19 that the deformation pattern is consistent with the collision. The front, driver's side is severely damaged to a maximum deformation of nearly 28 inches. In (b) note the additional distance between the right, rear wheel and the fender due to the body of the vehicle pitching 


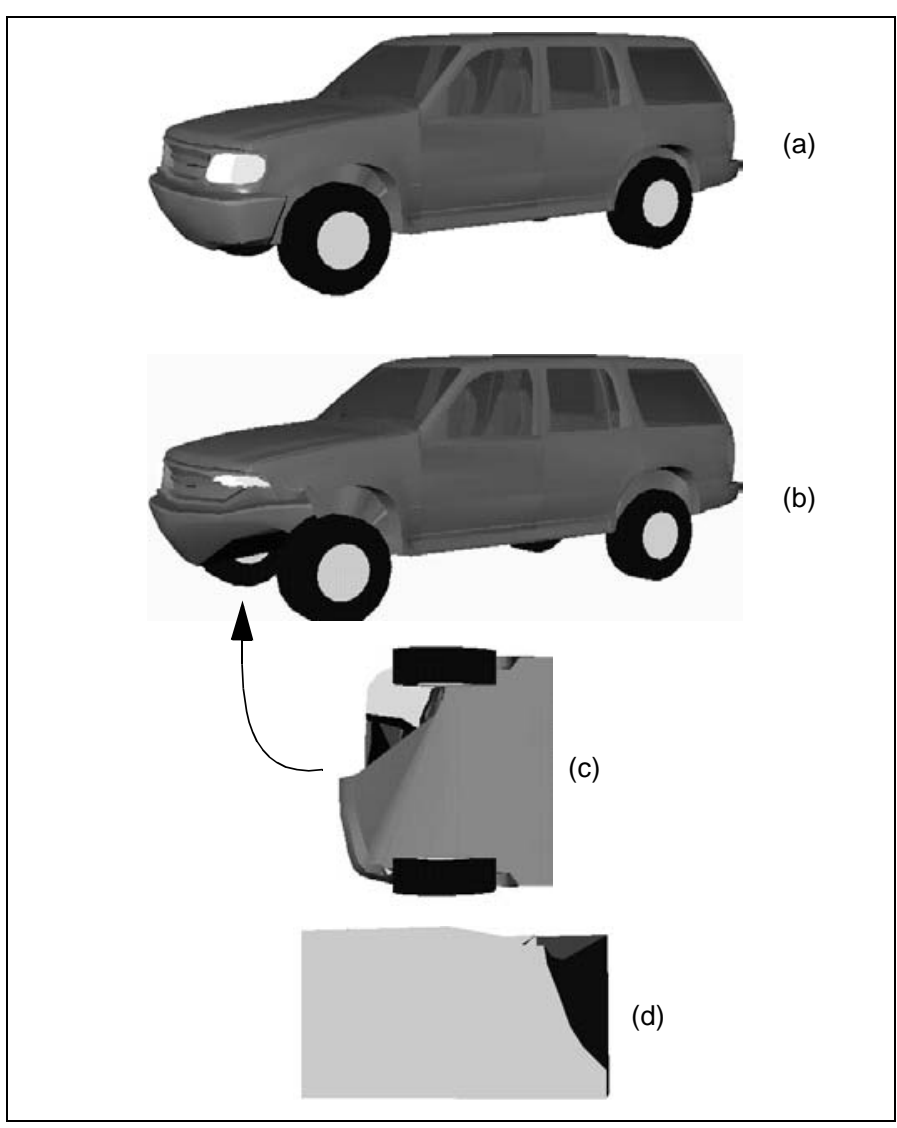

Figure 19. (a) Perspective View Before Damage, (b) After Damage at the Start of Rebound, (c) Bottom View After Damage, and (d) Top View of Deformed Barrier

and rolling during the collision. DyMESH does not currently model induced damage. The lack of induced damage is evidenced by the pristine hood shape in Figure 19(b).

Figure 20 shows the various load-deflection relationships used and the corresponding time histories of acceleration and velocity. The acceleration data for the test vehicle was digitized from the test report, and the velocity data was obtained by integrating the acceleration data.[5]

The early acceleration rise time is well matched by the simulations (Figure 20(b)). But, as time progresses the simulation system is stiffer which causes the peak acceleration to occur earlier than in the test. The stiffness may be due to the barrier model, the vehicle model, or both.

As in previous simulations, the differences in the velocity profiles are less than in the acceleration profiles (Figure $20(\mathrm{c}))$. The change in velocity in the three simulations agree within one-half mile per hour with each other and are close to the test result.

Figure 21 shows a time sequence of the collision event compared with images captured from the test video. As important as the comparison to data is the comparison of what the simulation "looks like" compared to the test. Here it is seen that the simulation has the same general response as the test vehicle. Some of the important features that the simulations share with the test are that the vehicle pitches forward upon impact, then rolls as it rotates around the barrier.

\section{CONCLUSION}

The DyMESH three dimensional collision algorithm has been used within the Human-Vehicle Environment (HVE) to simulate vehicle collisions with barriers. Collision forces generated by DyMESH were used as input to both a 3-DOF and 6-DOF solver. The simulation results were compared with test data. With simple force vs. deflection models DyMESH provides reasonable estimates of the acceleration history of the vehicle. For example, the peak accelerations agree to within $14 \%$ on average for all four simulations when using the quadratic force-deflection model (note: most of the error is in the Suburban simulation which over-predicted peak acceleration by $28 \%$ ). The best results are obtained on arguably the most challenging simulation - the offset, deformable barrier test. Here the DyMESH contact algorithm successfully prevents interpenetration of the vehicle meshes and produces reasonable deformation profiles.

It was shown that the form of the force-deflection model can dramatically affect the acceleration vs. time history response of the vehicle. Thus, simulations for which acceleration history is important (such as when occupant dynamics are being studied) should use the most accurate force-deflection model possible.

For most accident reconstruction applications, the use of a linear force-deflection relationship and the modified $A$ and $B$ coefficients are likely to be adequate. If required, more accurate force-deflection models may be deduced from test data on the same or similar vehicles or obtained from a finite element simulation. An efficient way to conduct an analysis may be to run a single finite element simulation to obtain a specific force-deflection model. Then many simulations could be run using DyMESH varying all of the other parameters that may be involved in a collision.

The simulation results showed that restitution and friction are important parameters and can effect the change in velocity and the vehicle trajectory.

Finally, the DyMESH algorithm continues to be a very promising approach for advancing the state-of-the-art in interactive collision simulation. More validations will be performed in the future including vehicle vs. vehicle collisions.

\section{CONTACT}

Allen R. York has worked in the area of computational mechanics for 11 years. Before forming A.R. York Engineering, Inc., he worked nine years at Sandia National Lab- 


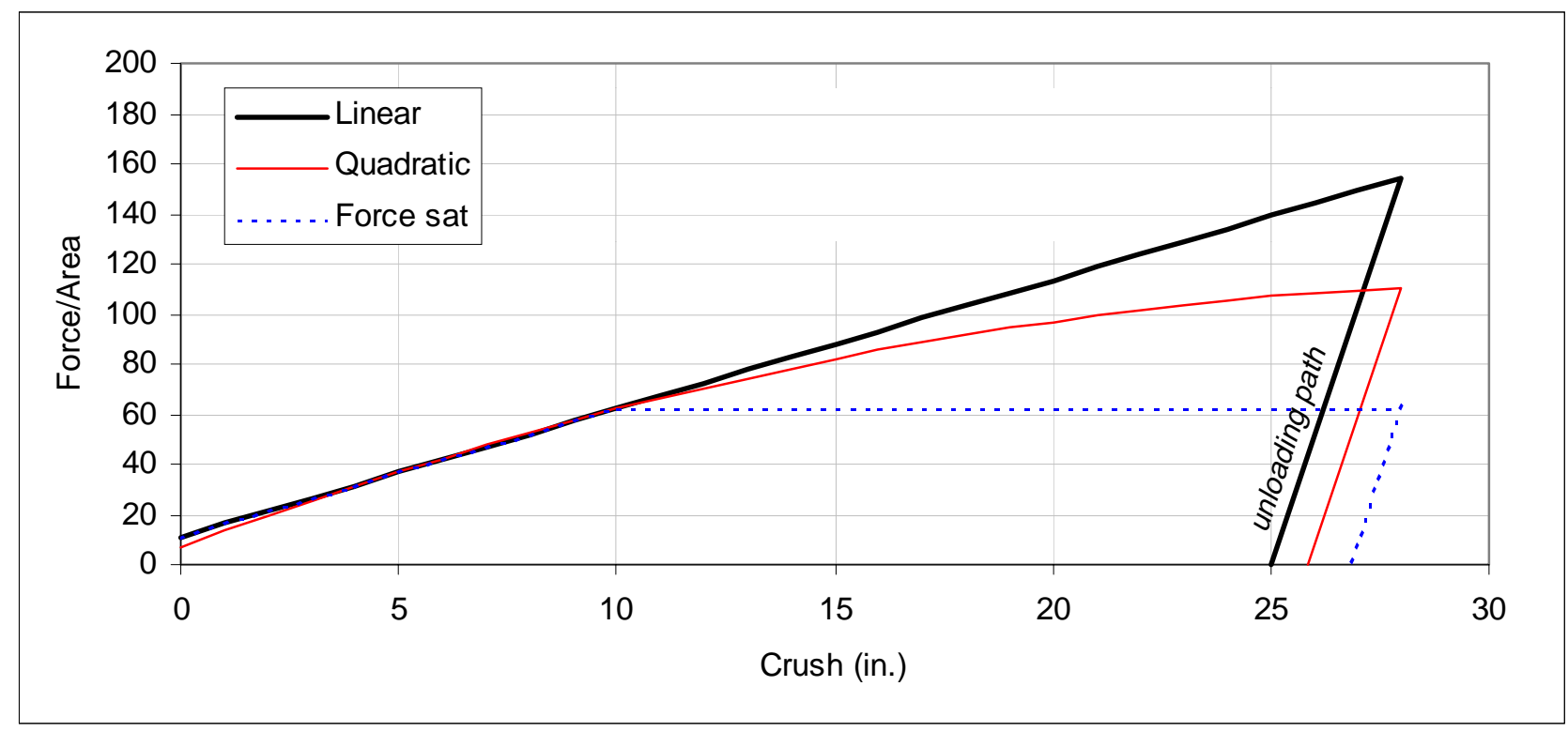

(a)

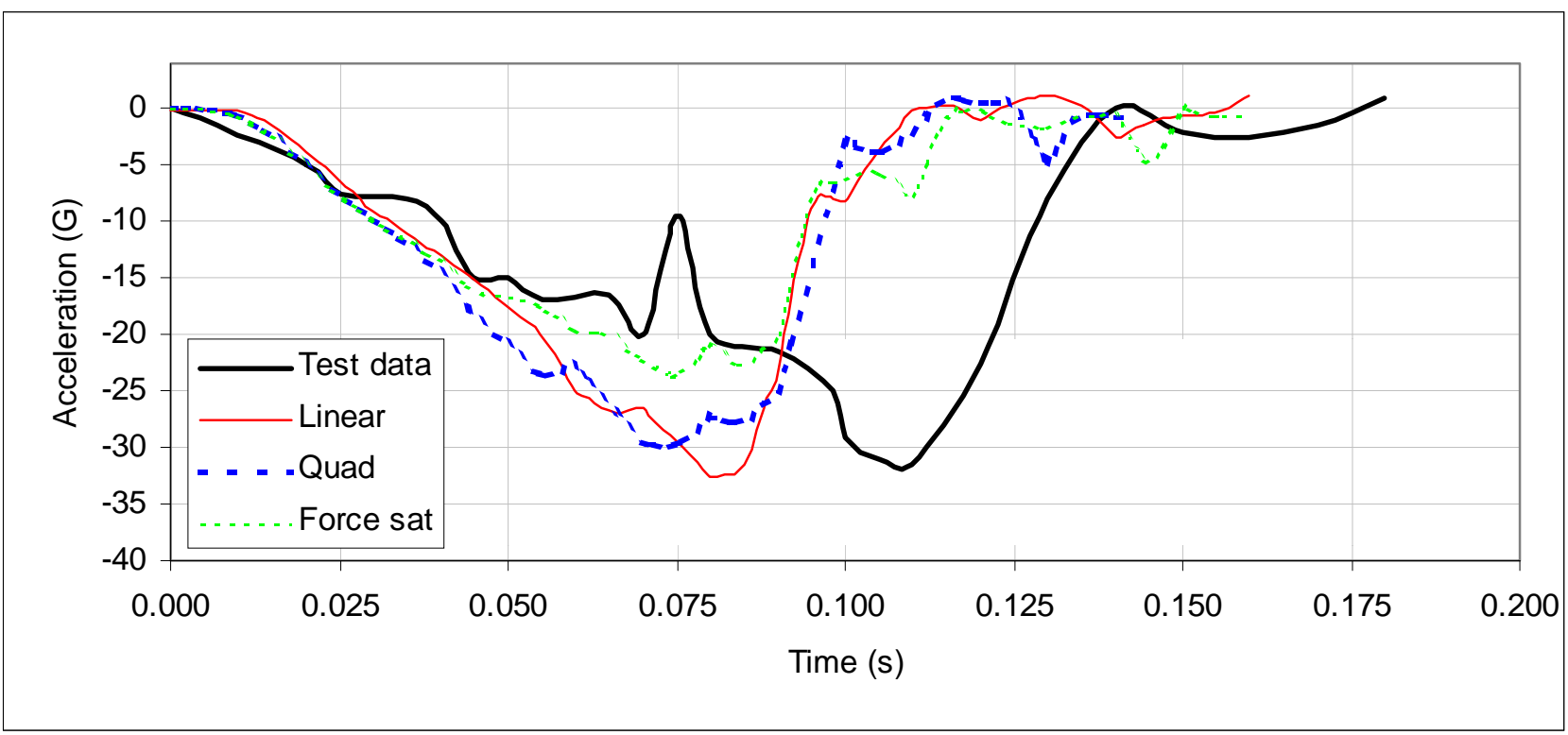

(b)

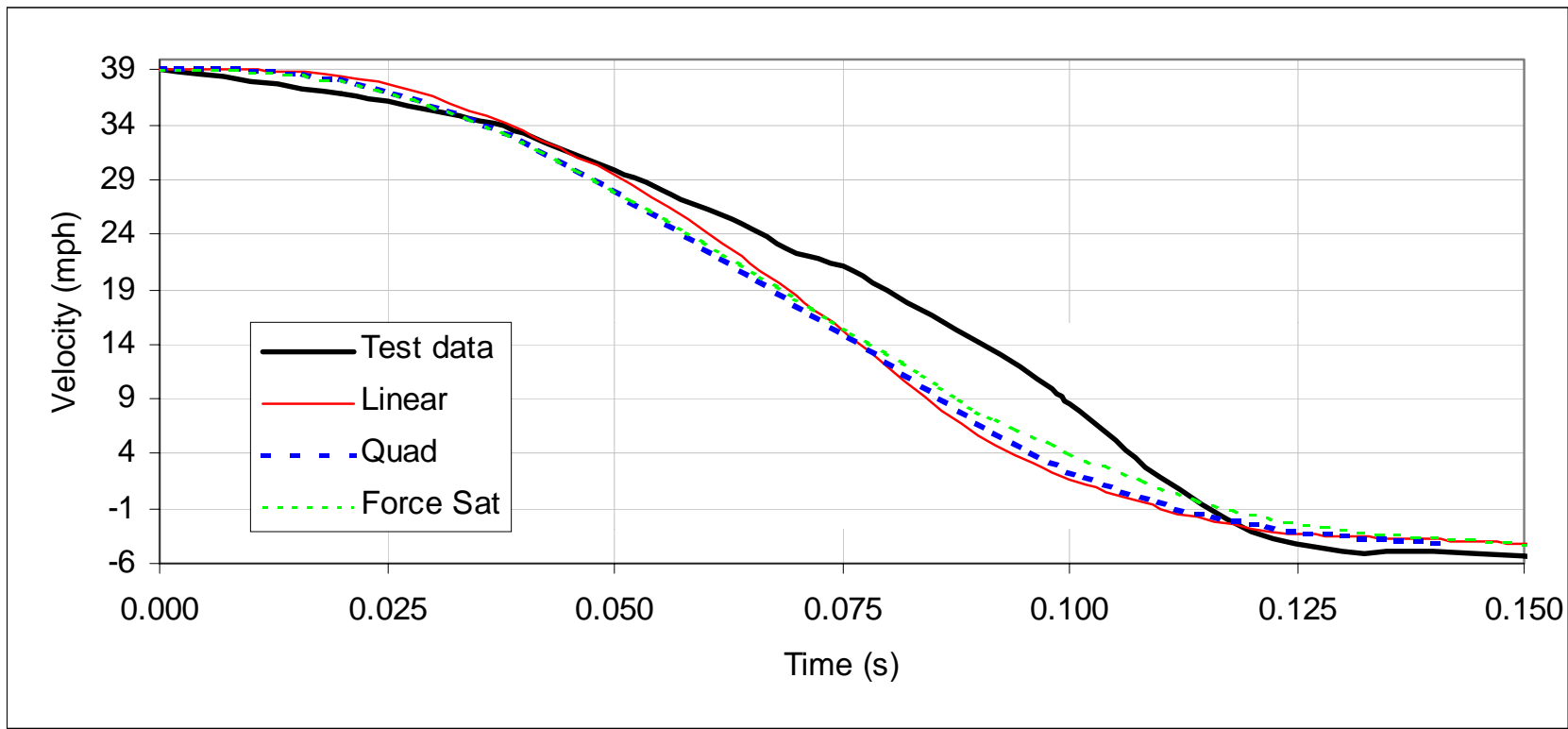

(c)

Figure 20. Ford Explorer Results: (a) Force-Crush Curves, (b) Comparison of $X$ Direction Acceleration Data, and (c) Comparison of $X$ Direction Velocity Data 


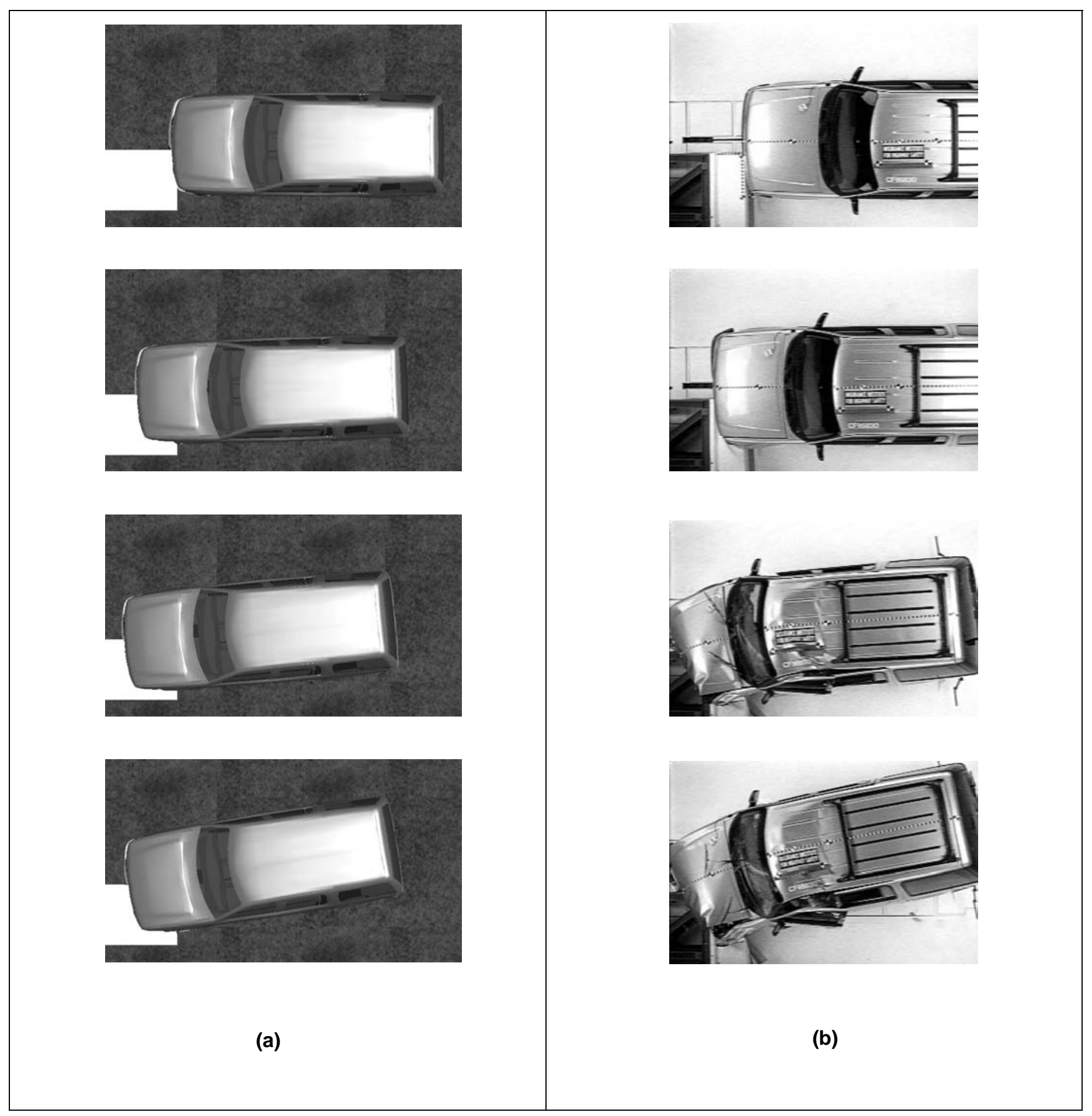

Figure 21. Comparison of Vehicle Trajectory: (a) DyMESH, (b) Test 
oratories. He can be reached by email at: aryork@flash.net.

Terry D. Day has worked in the area of motor vehicle handling and collision simulation for 18 years. He can be reached at Engineering Dynamics Corporation by email: day@edccorp.com. 


\section{REFERENCES}

1. York, A.R. and Day, T.D., "The DyMESH Method for ThreeDimensional Collision Simulation," SAE Paper No. 1999-010104, Society of Automotive Engineers, Warrendale, 1999.

2. Final Report, New Car Assement Program Frontal Barrier Impact Test, Report No. TRC-92-N07, TRC Test No. 930203, (NHTSA Test No. MP0103), February 26, 1993.

3. Final Report, Vehicle Safety Experimental Compliance Testing for Occupant Crash Protection, Windshield Mounting, Windshield Zone Intrusion, and Fuel System Integrity, Report No. 208-TRC-90-003, TRC Test No. 891215, (NHTSA Test No. CL0103), January 3, 1990.

4. Final Report, Moving Deformable Barrier Side Impact Test for Fuel System Integrity, 1993 Toyota Corolla 4-Door Sedan, CALSPAN Report No. 8102-5, CALSPAN Test No. Y47-0501287, May 21, 1993.

5. Insurance Institute for Highway Safety Crashworthiness Evaluation, Crash Test Report, 1996 Ford Explorer (CF95030), Insurance Institute for Highway Safety, Arlington, VA, October 1995.

6. National Highway Traffic Safety Administration, New Car Assessment Program (NCAP) Frontal Barrier Impact Test, U.S. Department of Transportation, Report No. MGA-96N018, September 23, 1996.

7. HVE Developer's Toolkit, Version 2, Engineering Dynamics Corporation, Beaverton, OR, October 1998.

8. McHenry, R.R., Jones, I.S., Lynch, J.P., "Mathematical Reconstruction of Highway Accidents - Scene Measurement and Data Processing System," Calspan Report No. ZQ-5341V-2, DOT HS-801 405, February, 1975.

9. Day, T.D., Hargens, R.L., "An Overview of the Way EDSMAC Computes Delta-V," SAE Paper No. 880069, Society of Automotive Engineers, Warrendale, 1988.

10. Campbell, K.L., "An Energy Basis for Collision Severity," SAE Paper No. 74565, Society of Automotive Engineers, Warrendale, 1974.

11. Day, T.D., "An Overview of the EDSMAC4 Collision Simulation Model," SAE Paper No. 1999-01-0102, Warrandale, 1999.

12. Strother, C.E., Woolley, R.L., James, M.B., and Warner, C.Y., "Crush Energy in Accident Reconstruction," SAE Paper No. 860371.

13. Kerkhoff, J.F., et. al., "An Investigation into Vehicle Frontal Impact Stiffness, BEV, and Repeated Testing for Reconstruction", SAE Paper No. 930899.

14. U.S. Department of Transportation, National Highway Traffic Safety Administration, "New Car Assessment Program (NCAP) Frontal Barrier Impact Test," Report No. MGA-96N018, September 23, 1996.
Reviewer's Discussion

By Thomas Perl, Collision Safety Engineering

SAE \# 2000-01-0844

Validation of DyMESH for Vehicle vs Barrier Collisions Terry D. Day, Allen York, Authors

The authors have continued to validate a new collision model to simulate automotive collisions. The collision model is a hybrid that advances the technology beyond a simple momentum exchange or simple linear homogeneous model as seen in SMAC. Yet, it avoids the complexity of a finite element model that greatly increases the complexity of the input parameters. The model also appears to recognize the importance of applying the collision forces opposite the direction of the body deformation.

Further study does appear fruitful in the area of restitution. The authors propose a restitution model that unloads at 10 times the loading stiffness. Work performed at our company suggests that a better restitution model would have the unloading curve immediately drop to a percentage of the maximum applied force and then unload at a slope similar to the linear loading curve. If the suggested restitution model were applied with the force saturated loading model (at a higher saturation level) better correlation with the test data would be achieved.

My final observation involved the offset barrier simulation. This simulation demonstrates the importance of obtaining stiffness coefficients from a similar test when ever possible. The stiffness coefficients obtained from the full frontal barrier test were obviously too stiff for each stiffness model applied.

I understand this collision model has not yet been implemented into any commercially available software. I am sure that will be remedied in the near future. Hopefully the authors will include the ability to define hard points within the vehicle, rather than having a homogeneous vehicle stiffness. It is often argued that the data is not available for a more complex vehicle stiffness model, but I argue that the data will not be forth coming unless there is the ability to utilize the data. I look forward to further research in this area. 
Reviewer's Discussion

By Michael S. Varat, KEVA Engineering

SAE \# 2000-01-0844

Validation of DyMESH for Vehicle vs Barrier Collisions

Terry D. Day, Allen York, Authors

The authors have presented validation work relating to a new analytical tool for accident reconstruction. The DyMESH collision simulation algorithm promises to be a useful tool for the realistic simulation and representation of vehicle crush response. As with any new tool, to fully exploit the capabilities of the DyMESH algorithm, input data to determine the vehicle structural stiffness properties are needed. These properties include the force deflection characteristics as well as the friction at the collision interface. As the authors noted, these structural properties will influence the vehicle acceleration time history as determined in the simulation. Therefore, as with any computer simulation, the input data used will determine the accuracy. While further DyMESH validation work to analyze vehicle to vehicle collisions is anticipated, additional refinement and analysis of vehicle force deflection response may be even more interesting. 